\title{
Ergonomics in Oral \& Maxillofacial Surgery: A Review
}

Dr. Sankara Rao Sanaka ${ }^{1 *}$, Dr. Rama Santhoshi Syamala Palivela ${ }^{2}$, Dr. Rahul Vinay Chandra Tiwari ${ }^{3}$, Dr. Heena Tiwari ${ }^{4}$, Dr. Dr. Vedatrayi ${ }^{5}$, Dr. Deepesh Mathur ${ }^{6}$

${ }^{1}$ 3rd Year Post Graduate Student, Oral and Maxillofacial Surgery, M.N.R.Dental College, mnr nagar, Fasalwadi, Sangareddy, Telangana 502294, India

${ }^{2}$ BDS, MS Environmental Occupational Health and Safety, Vijaya Santhoshi Dental Clinic, Kakinad

${ }^{3}$ FOGS, MDS, Assistant Professor, Department of Oral and Maxillofacial Surgery, Sri Sai College of Dental Surgery, Vikarabad, India

${ }^{4}$ BDS, PGDHHM, Government Dental Surgeon, Chhattisgarh, India

${ }^{5}$ MDS, Consultant Oral and Maxillofacial Surgeon, T. Nagar Chennai, Tamil Nadu 600017, India

${ }^{6}$ BDS (MBA), Admin, FMS Dental Hospitals, Hyderabad, Telangana, India

\section{DOI: $10.36348 /$ SJODR.2019.v04i09.001}

| Received: 16.08.2019 | Accepted: 03.09.2019| Published: 15.09.2019

*Corresponding author: Dr. Sankara Rao Sanaka

\section{Abstract}

Musculoskeletal disorders are of major concern among the medical practitioners. Most occupation-related musculoskeletal disorders arise due to motions that are repetitive, in addition to the operator maintaining a static position. Good ergonomic design of the workplace is a basic requirement for facilitating the balanced musculoskeletal health that will enable longer, healthier career, enhance productivity, and minimize occupation-related musculoskeletal disorders among oral \& maxillofacial surgeons. This review aims at highlighting the need for ergonomics in reducing occupationrelated musculoskeletal disorders in oral \& maxillofacial surgeons.

Keywords: Ergonomics, Musculoskeletal disorders, Good ergonomic design, enhance productivity.

Copyright @ 2019: This is an open-access article distributed under the terms of the Creative Commons Attribution license which permits unrestricted use, distribution, and reproduction in any medium for non-commercial use (NonCommercial, or CC-BY-NC) provided the original author and source are credited.

\section{INTRODUCTION}

Ergonomics can be defined as an applied science concerned with designing and arranging things people use so that the people and things interact most efficiently and safely [1]. In Greek, "Ergo," means work and, "Nomos," means natural laws or systems [2]. It is also a study of the relationship among the personnel, equipment and environment in the work area [3]. It takes account of the worker's capabilities and limitations in seeking to ensure that tasks, equipment, information and the environment suit each worker [4].

Musculoskeletal disorders are a wide range of inflammatory and degenerative disorders of muscles, tendons, and nerves. These disorders can result in pain and functional impairment affecting the neck, upper back, lower back, shoulders, elbows, wrists, and hands [5].

Professional induced musculoskeletal disorders have become more common these days. They are particularly seen in professionals requiring repetitive, forceful or prolonged exertions of the hands; frequent or heavy lifting, pushing or pulling, or carrying of heavy objects and prolonged awkward postures. The level of risk greatly depends on the intensity, frequency and duration of the exposure to the above mentioned conditions [1].

Oral \& Maxillofacial surgeons are one of the most susceptible professionals to such profession induced musculoskeletal disorders. Studies indicate that back, neck, and shoulder or arm pain is present in up to $81 \%$ of the operators [6]. Musculoskeletal disorders are caused by biomechanical load which is the force that must be applied to do tasks, the duration of the force applied, and the frequency with which tasks are performed. Most occupation-related MSDs are from motions that are repetitive, or from maintaining a static position [7].

\section{Mechanisms Leading To Musculoskeletal Disorders in Oral \& Maxillofacial Surgeons}

Prolonged Static Postures assumed by the operator during the surgical intervention can initiate a series of events that may result in pain, injury or musculoskeletal disorder [8]. During treatment, operators strive to maintain a neutral, balanced posture or at times attain an sustained awkward postures. These postures often lead to stressed shortened muscles which can become ischemic and painful, exerting asymmetrical forces that can cause misalignment of the spinal column [9]. During periods of prolonged static 
postures, when joints are restricted due to muscle contractions, synovial fluid production is reduced and joint hypomobility may result. In unsupported sitting, pressure in the lumbar spinal disks increases [8]. During forward flexion and rotation, a position often assumed by dental operators, the pressure increases further and make the structure vulnerable to injury [9].

\section{Signs of Musculoskeletal disorders [1]}

- Decreased range of motion

- Loss of normal sensation

- Decreased grip strength

- Loss of normal movement

- Loss of coordination.

\section{Symptoms of Musculoskeletal disorders [1]}

- Excessive fatigue in the shoulders and neck

- Tingling, burning or other pain in arms

- Weak grip, cramping of hands

- Numbness in fingers and hands

- Clumsiness and dropping of objects

- Hypersensitivity in hands and fingers.

\section{Ergonomics}

Ergonomics is the science of matching working conditions and human capabilities [10]. The basic idea is to allow the operator to perform work and other activities safely and efficiently. The basic principle in ergonomics is to match tools, equipment, and work methods to the needs of the operator in order to enable him/her perform comfortably to his/her best abilities. Thus, the need is to recognize conditions that lead to discomfort and implement changes to minimize or eliminate those conditions.

Ergonomics aims is to design the work area and the task around the human body, rather than force the worker to adapt to poor design and task function [11]. The Ergonomic Standard mandated by the Occupational Safety and Health Administration (OSHA) recommended that the most efficient and effective way to remedy "ergonomic hazards" causing musculoskeletal strain should be through engineering improvements in the workstation [2].

In dentistry, bad working habits, repetitive tasks - such as scaling, root planning, in addition to uncomfortable physical postures contribute greatly to musculoskeletal disorders, stress, and loss of productivity [12]. Four-handed dentistry is ergonomically the most favorable way to provide dental services since it minimizes undesirable movements of the operating team and expedites the progress of most dental procedures [13].

Research shows that maintaining the low back curve-the lumbar lordosis-when sitting can reduce or prevent low back pain [9]. Proper selection, adjustment and use of magnification systems have been associated with decreased neck and low back pain, as they allow operators to maintain healthier postures [14]. Alternating between standing and sitting also can be an effective tool in preventing injuries [9]. Operators should take the time to position their patients properly for mandibular and maxillary procedures. To prevent injury from occurring to muscles and other tissues, the operator should allow for rest periods to replenish and nourish the stressed structures. Operators may use various stress-reduction techniques to decrease stress related muscular tension [9].

Posture is considered the key to prevent the musculoskeletal disorders in operators. During minor oral surgical interventions, an Oral \& Maxillofacial surgeon attains a posture evolved from the orthostatic posture to a seated posture, especially on the account of adopting the concept of four hand dentistry [15]. Orthostatic posture is often adopted despite its many disadvantages, especially while performing the exodontia [16].

It is observed that when performing minor oral surgical procedures such as tooth extraction, dental graduates especially in their early career; when they start, dental clinics usually stand and perform exodontia [15]. A recent study had reported a high prevalence of knee disorders in students performing alveolar surgeries in an unfavorable standing posture [17].

Medical professionals are prone to unique muscle imbalances and require special exercise and ergonomic interventions to maintain optimal health during the course of their career. It is important to not only know what are effective interventions, but also in what sequence they should be implemented.

A recent study revealed that neck and shoulder pain is the most common complaint of the dentists under study, followed by pain in the wrist and elbow, and knee/foot pain. It also noted that medical professionals who do not perform any kinds of exercise in their daily life are more prone to musculoskeletal disorders among the dental surgeons [7].

\section{Future of Ergonomics}

Surgical intervention in the head \& neck region requires considerable concentration and attention to detail in addition to being long duration procedures requiring precision. Presently, the awareness pertaining to occupational hazards are increasing. Ergonomics have played a big role in controlling such hazards [18, 19]. Further development of medical ergonomics must arise on the basis of a coherent vision of the future. Aspects of particular interest are the prevention of occupational diseases, legal responsibility for protecting the health and safety of employees and students, education in dental ergonomics for dental and oral hygiene students, the academic development and research of dental ergonomics, using organizational 
models in daily dental practice, and the development of ergonomics at the global level $[18,19]$.

\section{CONCLUSION}

Musculoskeletal disorders in medical professionals result in loss of work efficiency. The prevalence and severity of these disorders can only decrease by adopting ergonomic interventions. Interventions or prevention strategies require an awareness of how to fit the task to the operator and not the operator to the task. Applying ergonomics to the field of Oral \& Maxillofacial surgery could improve performance objectives through greater productivity. The ergonomics and healthy workplace help the dental surgeons increase their performance without putting at risk their own health. One of the main goals of ergonomics is to minimize the amount of physical and mental stress that sometimes occurs day to day in a dental practice.

\section{REFERENCES}

1. Gupta, A., Manohar Bhat, T. M., Bansal, N., \& Gupta, G. (2014). Ergonomics in dentistry. International journal of clinical pediatric dentistry, 7(1), 30-34.

2. Nutalapati, R., Gaddipati, R., Chitta, H., Pinninti, M., \& Boyapati, R. (2009). Ergonomics in dentistry and the prevention of musculoskeletal disorders in dentists. Internet $J$ Oсcup Health, 1(1), 1-9.

3. Russell, J. G. (1973). Ergonomics in the dental surgery. Occupational medicine, 23(4), 128-131.

4. Kahri, P. (2005). Ergonomics and teamwork in dental treatment. Planmeca Oy, 1-2.

5. Buckle, P. W., \& Devereux, J. J. (2002). The nature of work-related neck and upper limb musculoskeletal disorders. Applied ergonomics, 33(3), 207-217.

6. Valachi, B., \& Valachi, K. (2003). Mechanisms leading to musculoskeletal disorders in dentistry. The Journal of the American Dental Association, 134(10), 1344-1350.

7. Roshene, R., \& Loganathan, S. (2017). Ergonomics and Musculoskeletal Disorder as an Occupational Hazard in Dentistry-A Pilot Study. Journal of Pharmaceutical Sciences and Research, 9(5), 712-715.
8. Al Wassan, K. A., Almas, K., Al Shethri, S. E., \& Al Qahtani, M. (2001). Back \& neck problems among dentists and dental auxiliaries. J Contemp Dent Pract, 2(3), 17-30.

9. Bramson, J. B., Smith, S., \& Romagnoli, G. (1998). Evaluating dental office ergonomic risk factors and hazards. The Journal of the American Dental Association, 129(2), 174-183.

10. Shaik, A. R. (2015). Dental ergonomics: Basic steps to enhance work efficiency. Archives of Medicine and Health Sciences, 3(1), 138-144.

11. Donis, E. T. (2007). Ergonomics for the Dental Hygienist. Practical Hygiene; 35-39.

12. Szymanska, J. (2002). Disorders of the musculoskeletal system among dentists from the aspect of ergonomics and prophylaxis. Annals of Agricultural and Environmental Medicine, 9(2), 169-173.

13. Finkbeiner, B. L. (2000). Four-handed dentistry revisited. J Contemp Dent Pract, 1(4), 74-86.

14. Napoletano, D. (2007). Dental Operating Microscopes: Don't Equip an Operatory Without One. Inside Dent, 3(5).

15. Gadicherla, S., Pentapati, K. C., Singh, A., John, E. R., \& Smriti, K. (2018). Evaluation of a new ergonomic position for the operator/clinicians for the extraction of mandibular right posterior molar teeth. Journal of International Oral Health, 10(1), 36-39.

16. Anghel, M., Argeanu, V., Talpo, C., \& Lungeanu, D. (2007). Músculoskeletal disorders (MSDS) consequences of prolonged static postures. J Exper Med Surg Res, 4, 167-172.

17. Yi, J., Hu, X., Yan, B., Zheng, W., Li, Y., \& Zhao, Z. (2013). High and specialty-related musculoskeletal disorders afflict dental professionals even since early training years. Journal of Applied Oral Science, 21(4), 376-382.

18. Thornton, L. J., Stuart-Buttle, C., Wyszynski, T. C., \& Wilson, E. R. (2004). Physical and psychosocial stress exposures in US dental schools: the need for expanded ergonomics training. Applied ergonomics, 35(2), 153-157.

19. Hokwerda, O. (2008). Vision of the future of ergonomics in dentistry. Nederlands tijdschrift voor tandheelkunde, 115(8), 429-434. 